\title{
3D GIS for Building Archaeology. Combining Old and New Data in a Three-dimensional Information System in the Case Study of Lund Cathedral
}

\author{
MARTINA POLIG, Lund University, Sweden
}

Traditionally, building archaeology is conducted by creating and interpreting 2D documentation, even though the spatial properties of a building are not fully expressed in $2 \mathrm{D}$. The third dimension has been mostly neglected, due to technical limitations that can be overcome through the rapid progress in 3D technology.

This study shows how a 3D GIS can be applied from the outset of a building archaeological study to create a three-dimensional information system connected to a geometrically accurate 3D model of a structure. The building under investigation was Lund Cathedral (Sweden), whose long and complex history has been studied for two centuries. Gaining an understanding of all interventions, as well as managing the heterogonous datasets, is a challenge.

In order to overcome these difficulties, various datasets and their relevant metadata were imported into the ArcGIS software and linked to a geometrically accurate 3D model of the church, placing all pieces of information in their correct spatial position. Thus, data that was previously impossible to view simultaneously and in the same space can be displayed together, creating a unique holistic oversight of the available material. Through the flexibility and versatility of the system, information can be displayed and queried at will, as well as updated continuously, greatly facilitating interpretation and making it an important resource throughout the entire building archaeological study.

Key words:

3D GIS, Building Archaeology, 3D Model, Information System.

SDH Reference:

Martina Polig 2017. 3D GIS for Building Archaeology. Combining Old and New Data in a Threedimensional Information System in the Case Study of Lund Cathedral. SDH, 1, 2, 225-238.

DOI : $10.14434 /$ sdh.v1i2.23253

\section{INTRODUCTION}

For decades, GIS has been an integral part of archaeological practice and its many advantages and uses in visualizing and managing archaeological data have been discussed as well as examined from

The work for this article was funded by the C.M. Lerici Foundation in Stockholm and was carried out in collaboration with DARK-Lab at Lund University and the "Lund Cathedral 2023" project.

Author's address: Martina Polig, Science and Technology in Archaeology Research Center (STARC), Athalassa Campus, 1545 Nicosia, Cyprus; email: martina.polig@gmail.com

Permission to make digital or hardcopies of part or all of this work is granted without fee according to the open access policy of SDH.

(C) 2017 SDH Open Access Journal 
a critical and theoretical perspective [Lock 2001; Wheatley and Gillings 2002; Conolly and Lake 2004; Frischer 2008; Hacigüzeller 2012]. The potential for using a three-dimensional environment and 3D data in a GIS has also been part of this discussion. The first attempts in using a 3D GIS on an intrasite level was through the characterization of archaeological features with polylines, polygons, points or volumes, visualized in a three-dimensional environment of a GIS [Doneus and Neubauer 2005; Losier et al. 2007; Katsianis et al. 2008]. Even though accurate three-dimensional models through laser scanning or photogrammetry were available, it was difficult to implement them in a GIS due to the limited visualization capacities of geometrically-complex 3D models; even so, some attempts have been made to combine 3D models with GIS [Allen et al. 2004; Doneus and Neubauer 2005].

Many of the 3D models generated within building archaeology, be they reconstructions with CAD or mesh from photogrammetry or laser scanning, were not implemented in information systems but used for other purposes, for example, to generate 2D documentation [e.g., Jones 2011]. Nevertheless, the potential of linking 3D models of buildings to additional information was recognized, but, owing to the difficulties in implementing such models into a GIS, other ways of realizing this were found with game engines and web applications [De Luca et al. 2011; Kurdy et al. 2011; Agugiaro and Remondino 2014].

Thanks to recent technical developments, the implementation of complex texturized threedimensional geometries in a GIS software is now possible; several case studies have explored the new possibilities that this advance has brought to archaeological research [Forte et al. 2015; Dell'Unto et al. 2016; Landeschi et al. 2016]. The present study will contribute to this line of research by investigating how heterogeneous datasets connected to a building archaeological study can be implemented directly into one geographical information system, while also exploiting the three dimensionality of the work space and the object of study fully. This has been accomplished by linking multi-resolution models of the building under investigation, Lund Cathedral, with heterogeneous data, using the models as "containers" and context without resorting to hyperlinks.

\subsection{The case study: Introducing Lund Cathedral}

Lund Cathedral is situated in the heart of the city Lund in the south of Sweden. The Romanesque church dates back to the twelfth or thirteenth century and soon became the ecclesiastical center of Scandinavia. During its history, it has been modified and renovated multiple times as well as investigated from an architectural and archaeological point of view [Rydén and Lovén 1995]. The large amount of data created in these studies is now being expanded by the interdisciplinary research project "Lund Cathedral 2023", which has been initiated in light of the upcoming 900th anniversary of the church in 2023. The aim of this project is to collect, revise and update the knowledge that has been gathered around Lund Cathedral. Managing and gaining an understanding of such large datasets, comprising also point clouds from a recent laser scanning and photogrammetry acquisition campaign, constitute a challenge. The availability of the 3D documentation of the entire structure made Lund Cathedral an ideal case study for testing the implementation of 3D models of an entire building into a GIS, making it the center of a threedimensional information system containing heterogeneous datasets. 


\section{CREATING A THREE-DIMENSIONAL INFORMATION SYSTEM}

For the development of the three-dimensional information system we chose to use ArcGIS Pro from ESRI, which offers a good performance for visualization and manipulation of data in a 3D environment.

The different datasets that were incorporated into the system comprised 3D models, 2D data generated from the 3D models, excavation maps and sections, archaeological drawings, text information and photographs (Fig. 1). The heart of the system is the 3D models that functioned as "containers" and as context for the rest of the data. Due to the size of the cathedral and the dataset and the limited timeframe of the study, it was necessary to restrict the area of research to the crypt in the eastern part of the cathedral. The crypt was chosen because it constitutes a closed environment in itself and its size is manageable for the time period of the project.

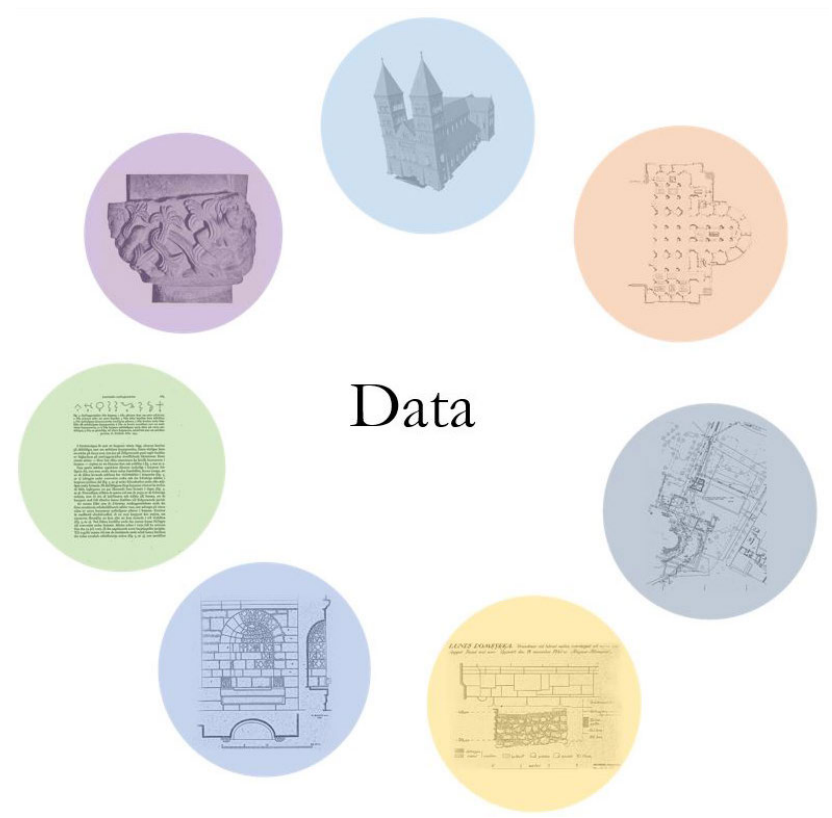

Figure 1. The heterogeneous datasets implemented in the system: 3D models, $2 D$ data generated from the 3D models, excavation maps and sections, archaeological drawings, text information and photographs.

\subsection{D models}

Three different resolutions of 3D models from three different acquisition campaigns were imported into the system and georeferenced. The first model (Fig. 2), which serves as a visual and contextual reference for the others, was received from the Lund Cathedral 2023 project. It is a low-resolution model of the entire cathedral that was created through image-based modeling and from pictures taken by a drone. It was georeferenced by aligning it to a partial model of the cathedral, created by the author also through image-based modeling and georeferenced in Photoscan with GPS points. All the other models were aligned to this model, and thus georeferenced as well, in the open source 
software CloudCompare, which can visualize georeferenced models and save the correct coordinates without shortening them.

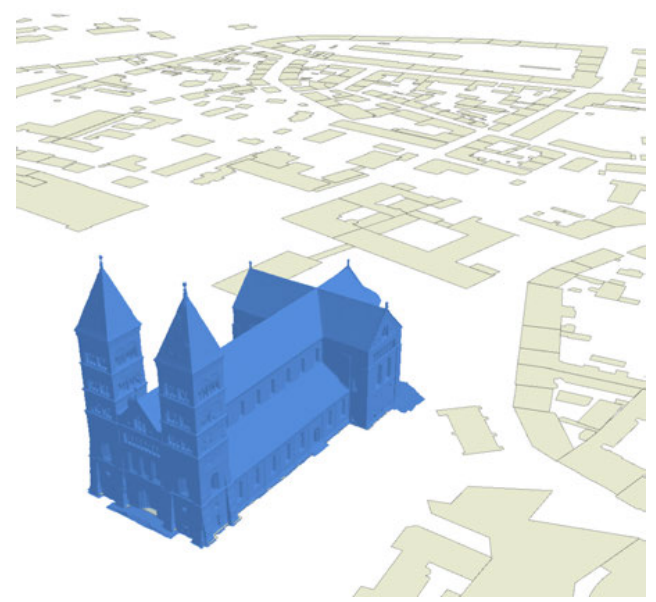

Figure 2. Low-resolution 3D model of the entire cathedral.

On the next level of resolution is a 3D model of the entire crypt that is quite accurate in its detail and is based on laser scan point clouds from an acquisition by Lund University (Fig. 3). The point clouds were cleaned and meshed in the open source software Meshlab. In order to be able to import such a detailed mesh to the GIS it was necessary to divide it into four models, each with around five million faces.

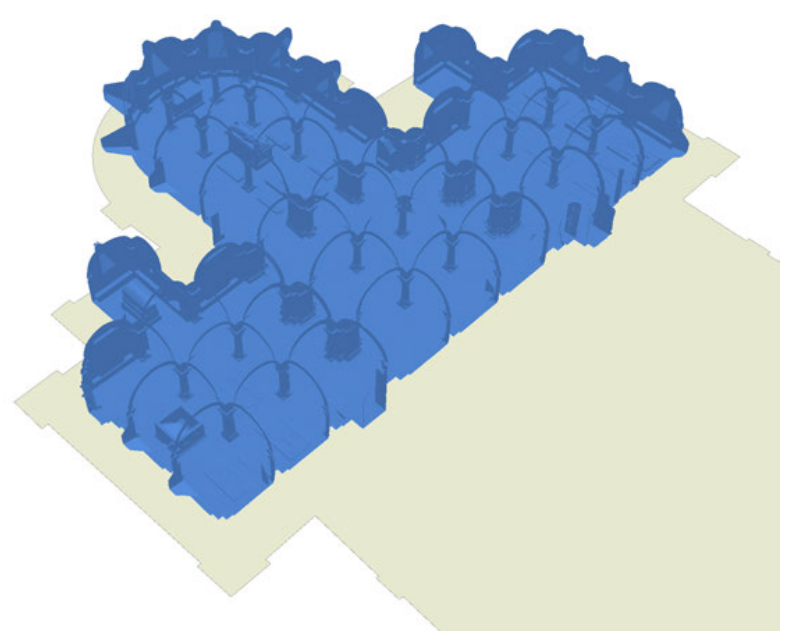

Figure 3. 3D model of the crypt, divided in four smaller parts with each one around 5 million faces.

The models with the highest level of detail are the walls of the crypt, divided into smaller sections with each one having about 2 million faces (Fig. 4). These models were made from the high-density point clouds from a laser scan acquisition by the company SWECO, which was commissioned by the Lund Cathedral 2023 project to scan the entire cathedral. They were cleaned and meshed in the 
software CloudCompare, which is more adapted to very large point clouds compared to Meshlab. A very high resolution was necessary for these models in order to allow users to distinguish single stones in the walls. This makes it possible to make a wall analysis directly on the 3D model by identifying and characterizing with polygons different phases in the wall (see Fig. 4). These polygons are linked to an attribute table that can be customized and contains additional information about a specific wall part, such as the dating, the level of degradation, etc.

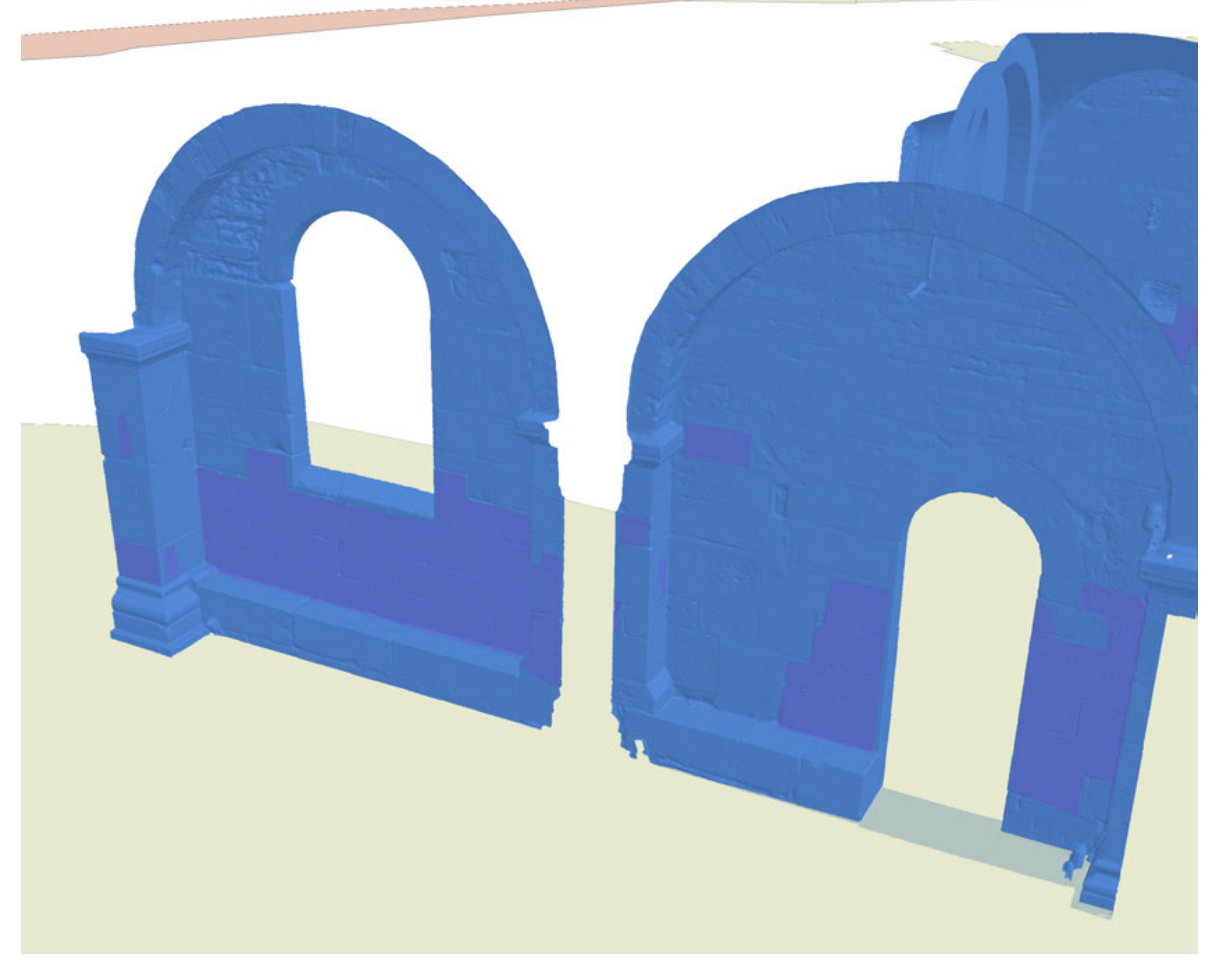

Figure 4. High-resolution models of the walls in the crypt that allow users to distinguish single stones in the walls. Polygons (in purple) were drawn directly on the 3D model, characterizing repair works from the nineteenth century.

\subsection{D data from 3D models}

3D models of structures and buildings are often used to create traditional documentation like plans and sections. These can be integrated as well into the GIS, visualizing them together with the 3D models. As an example, for this study, sections of the crypt at regular intervals of $50 \mathrm{~cm}$ were created in CloudCompare. They were imported into the GIS as raster, georeferenced and then moved on the z-axis to the height at which they were taken (Fig. 5). 


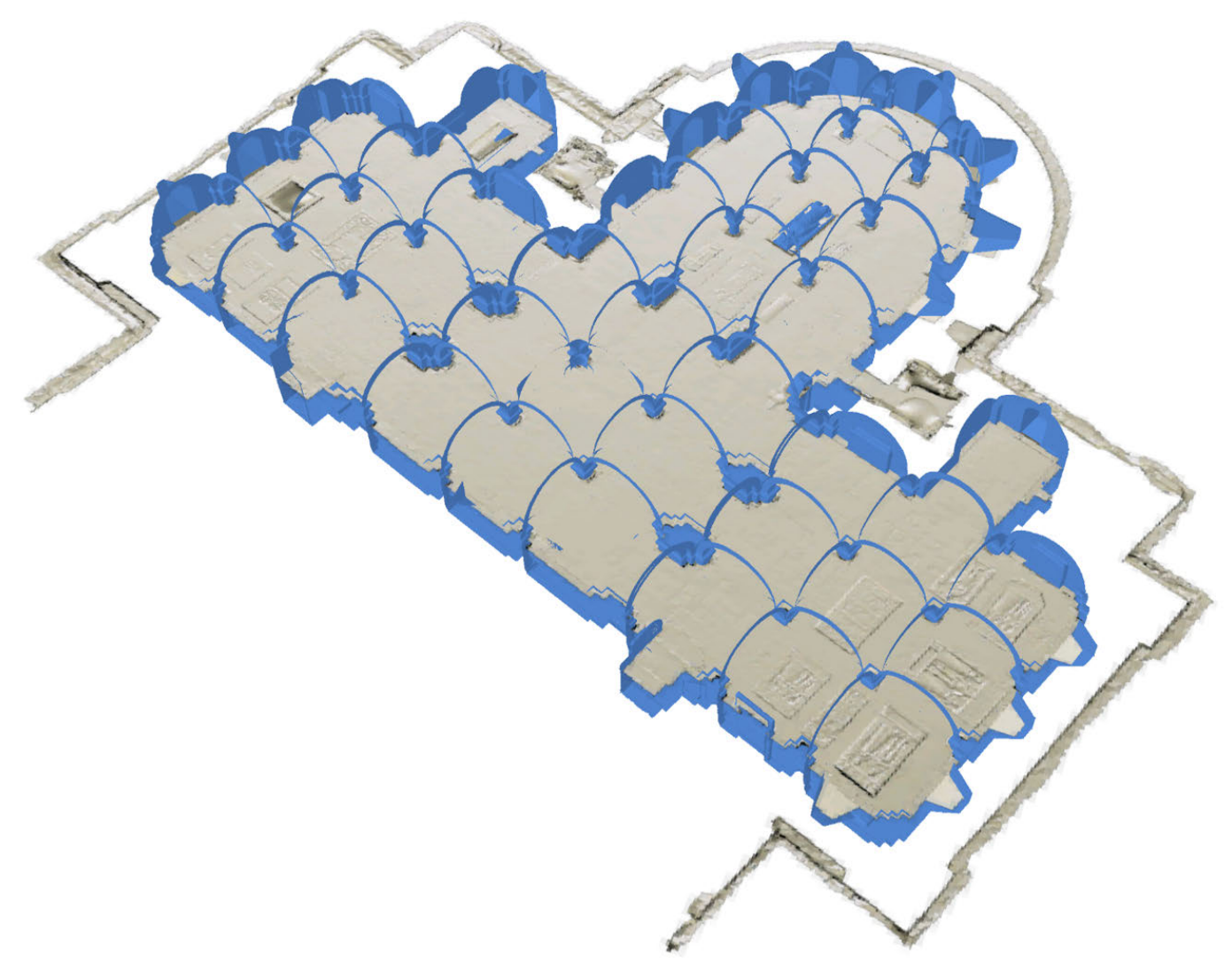

Figure 5. Section generated by a cut through the 3D models of the cathedral and visualized with the 3D models at the height at which it was taken.

\subsection{Excavation maps}

Studies of buildings often also include excavation documentation. In case of Lund Cathedral, there were several excavations conducted within and outside the church over the last century. A cumulative excavation plan that shows all the excavation trenches of the twentieth century was imported as a raster and georeferenced in the GIS (Fig. 6). Trenches of more interest were vectorized by drawing polygons and then connected with additional information through the attribute table (year, findings, etc.). In this way, the original cumulative excavation map has become much more easily readable and clearer, with single excavations represented as layers, which can be visualized and queried at will. If more detail is necessary, the individual trenches can easily be integrated with further related excavation material in form of maps, sections or finds. 


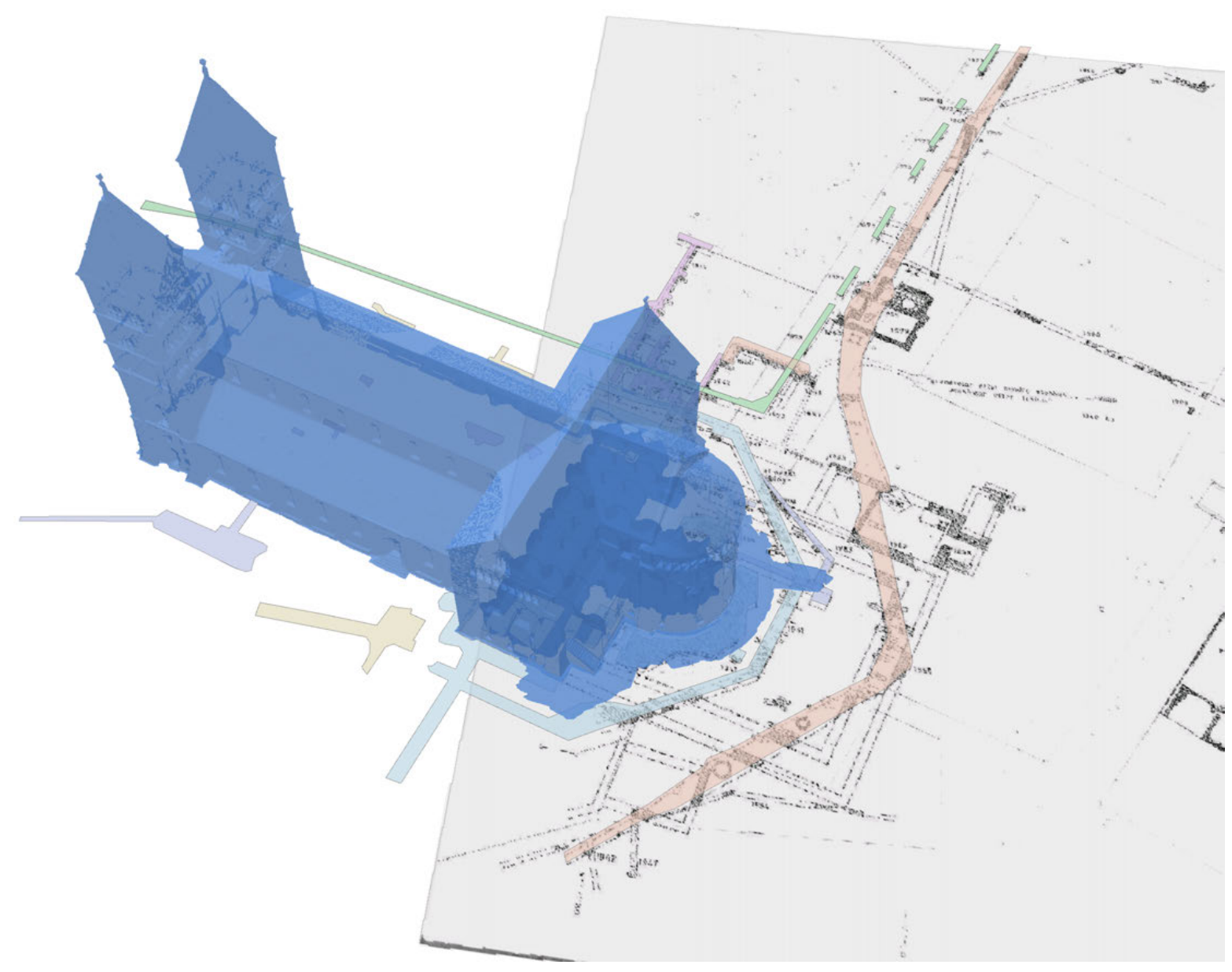

Figure 6. Cumulative excavation map imported into the GIS and visualized with the 3D model of the entire cathedral in transparency and the crypt. Trenches of interest were redrawn with polygons and connected to an attribute table. The different colors of the trenches symbolize different years of excavations.

\subsection{Sections}

Even though sections are part of traditional excavation documentation, they have been treated separately from the maps in this study because they constitute vertical and not horizontal information. The possibility of working in a three-dimensional environment is of particular importance with sections, because it allows us to visualize them with their true orientation and in relation to horizontal information.

As an example, a section of an excavation trench in the corner between the northern side aisle and the northern transept of the cathedral was chosen (Fig. 7a). The scanned drawing of the section was imported, scaled and vectorized in the GIS. Additional information, e.g. about the material, was added in the attribute table. The drawing was then exported into AutoCad to perform the necessary rotation to put it in a vertical position, an operation that is unfortunately not yet possible in ArcGIS Pro. After being reimported in the GIS it was put in its correct position. 
Unfortunately, there was no exact information about the position of this section available other than a description of its location on the drawing itself (Fig. 7c). Nevertheless, it was possible to place the drawing accurately thanks to an alignment with a 3D model of the cathedral. In fact, the drawing shows also part of the wall of the cathedral above ground that was acquired through laser scanning. A highly detailed mesh of the relevant part was created and aligned to the low resolution overall model of the entire church. The stones visible in the mesh and on the drawing were then used as references for placing the drawing correctly in the space.

a)

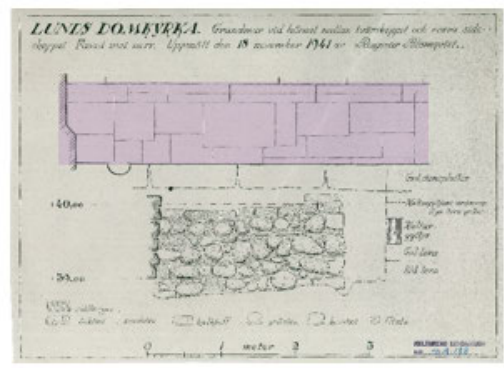

b)

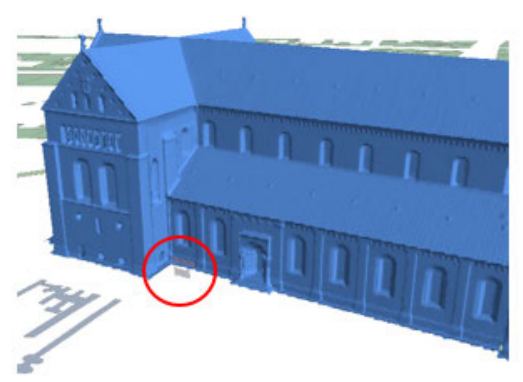

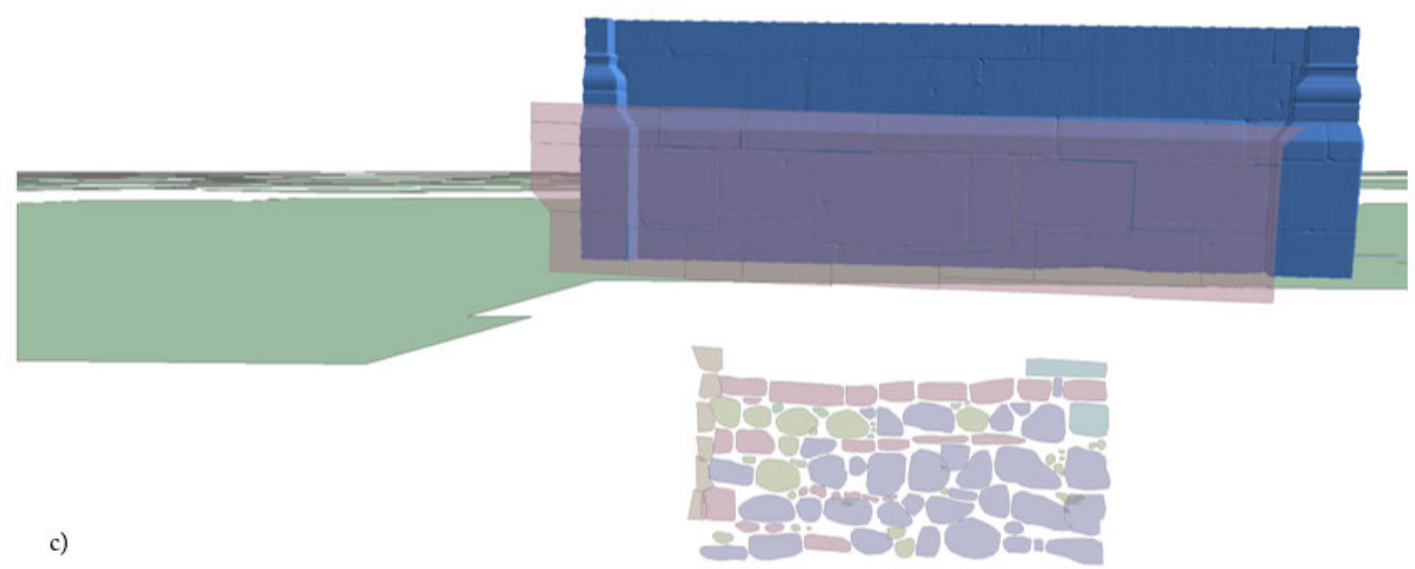

Figure 7. (a) The original drawing of a section at the northern transept with the area above ground visible also on the $3 \mathrm{D}$ model highlighted in pink. (b) The section visualized together with the overall 3D model of the church, encircled with red. (c) A close up of the section and the high-resolution model used to position the section. It was decided to visualize the different materials of the stones (information stored in the attribute table) with different colors.

\subsection{Archaeological drawings}

Archaeological drawings are part of the traditional documentation material available on the cathedral, and it was necessary to find a way to incorporate them directly into the GIS. This can be achieved by applying the drawings as textures on the 3D models. 
A drawing of the southern niche in the northern chapel of the crypt was chosen; it was created in the first half of the twentieth century. It depicts decorations in and around the niche that are now only partially visible and only in certain light conditions. A low-resolution model of the niche and the surrounding wall was created in Meshlab. The drawing was added to the scene in Meshlab and draped over the model as texture. The texturized model could then be imported into the GIS, where the drawing can be visualized and placed in the context of the rest of the crypt (Fig. 8).

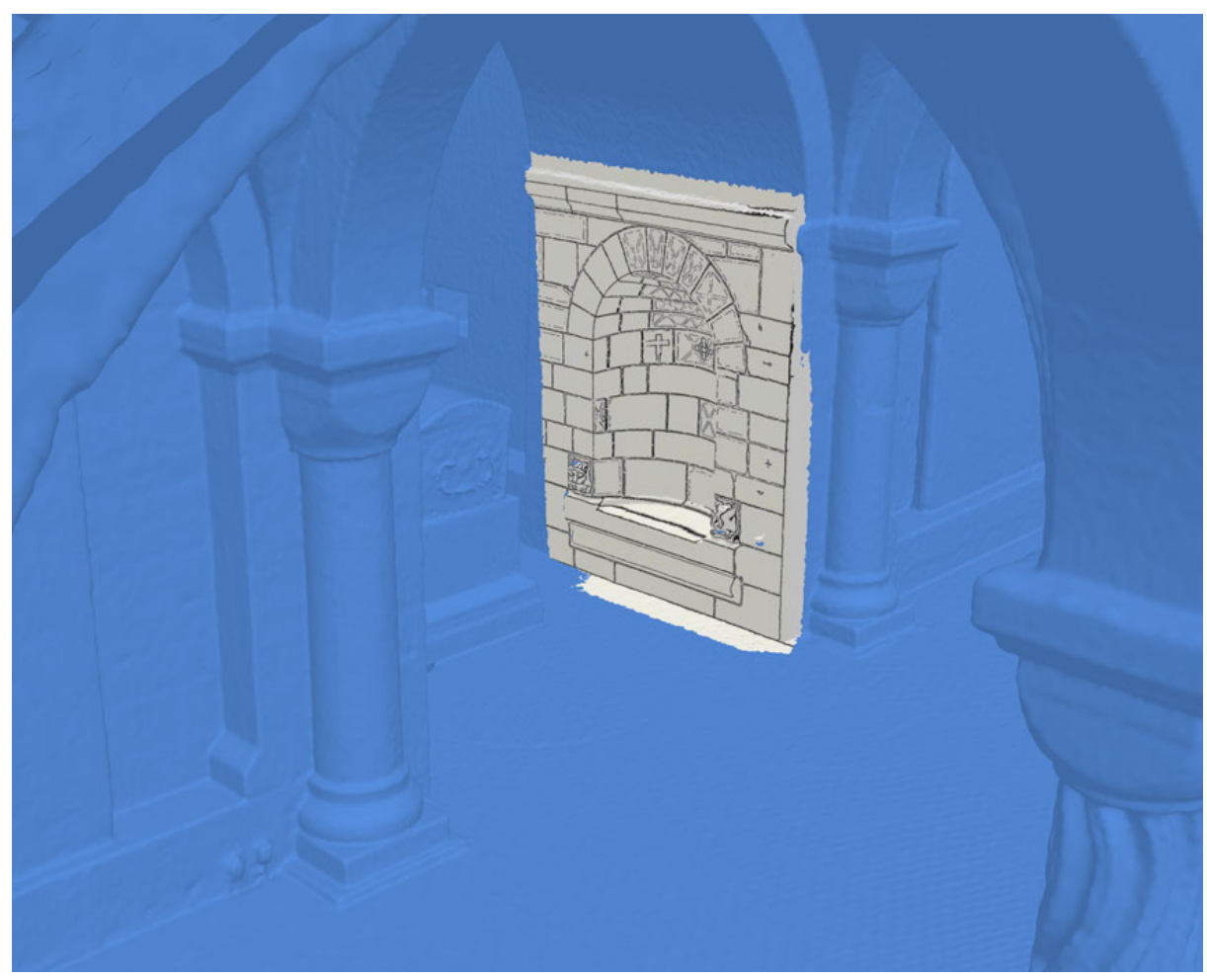

Figure 8. Archaeological drawing of a niche in the northern part of the crypt imported into the system by using it as a texture on a 3D model of the niche.

\subsection{Text information}

The literature about a structure may also contain information about things or elements that have a specific position in relation to the structure (burials, specific decorative elements, inscriptions and graffiti, etc.) but have for one reason or another never been visualized in a drawing. In the case of the cathedral in Lund there are several researchers [e.g. Rydbeck 1953; Cinthio 1957] who discuss the stonemason signs in the cathedral, sometimes with detailed descriptions of the location of some of the signs. However, only a few archaeological drawings of other architectonic elements exist on which the signs have also been represented and no map or drawing is available that shows all the signs. This is most likely due to the difficulty of representing with traditional means the hundreds of signs that are distributed over the entire church and at various heights. 
In the GIS system, each stonemason sign can easily be represented by a point on its exact position on the 3D model. Information about the dating and type of sign can be stored in the attribute table (Fig. 9).

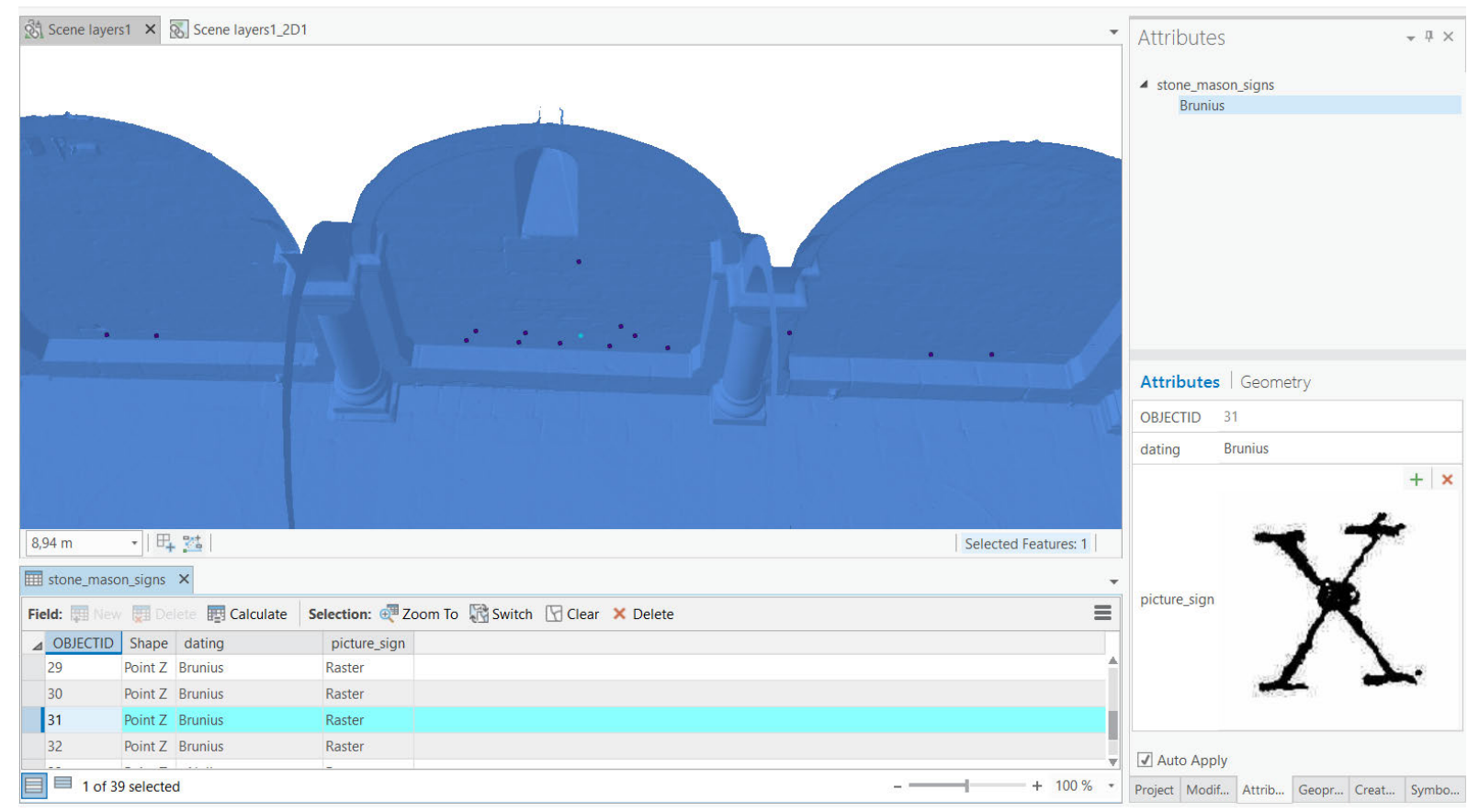

Figure 9. Stonemason signs mapped directly onto the 3D models as points, along with the corresponding attribute table, which contains information about the dating and a picture of the type of sign for each point.

\subsection{Photographs}

Photographs were also incorporated into the system, by implementing them directly into the attribute table. In this way, each feature can have one raster associated with it. It is of particular use in cases where a feature is not or only poorly represented as a 3D model and it is thus not possible to have an immediate visual understanding of what it looks like. This can be the case when a mesh is not detailed enough to properly represent a certain element, for example, the decoration on some of the capitals in the crypt (Fig. 10). If something that is not present anymore in the buildings is signed in with a polygon or a point (e.g. finds), or if it is too small to show on a 3D model, for example, the stonemason signs in this case study, adding a photograph serves as an aid to immediately understand what is referred to (Fig. 9). 


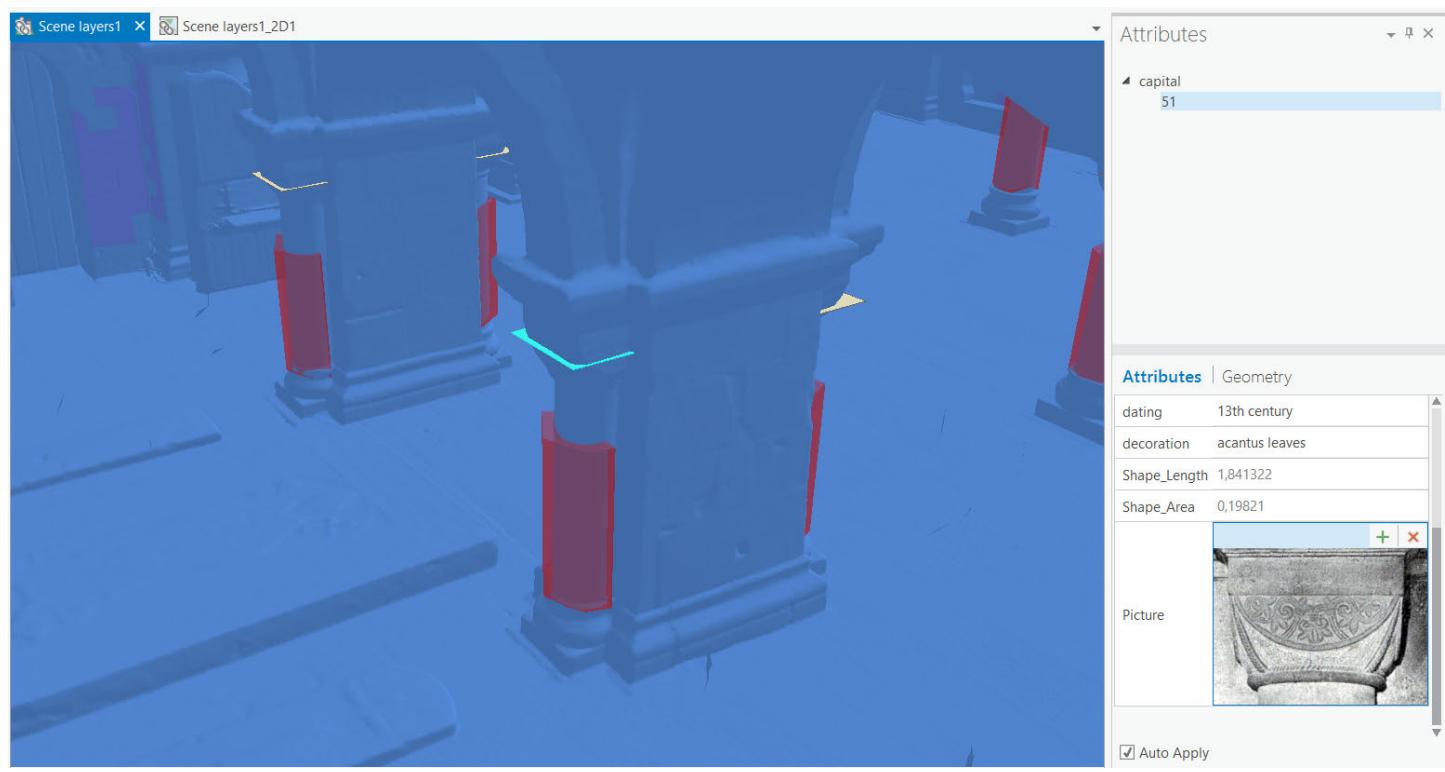

Figure 10. Capitals and column shafts characterized with simplified geometries of respectively rectangles in yellow and cylinders in red. The only capital with a decoration of acanthus leaves in the crypt is selected (light blue rectangle) and its attributes made visible, including also an image.

\section{DISCUSSION}

The aim of this study-to test how different kinds of datasets typically associated with building archaeology can be implemented in a 3D GIS linking them directly with 3D models of a building-was successfully achieved. All datasets could be inserted into the system, benefitting directly from its three-dimensionality. The only exceptions are the excavation maps and the photographs, which could also be inserted in the same way in a 2D space and would only profit from the third dimension by being visualized in relation to the rest of the data. Once all the data was imported it could be manipulated and investigated to promote interpretation and understanding through queries and measurements and by creating new data.

However, the implementation of certain datasets has already created an additional value impossible to achieve without 3D. A part of the 3D models themselves and the archaeological drawings which were attached to the 3D models as textures; this is the case for sections taken from the 3D models which can be added at the exact position at which they were taken, showing how the thickness of the walls varies at different heights (Fig. 5). In this category also belong the excavation sections, which can be imported vertically and could, coordinated with maps of the trench in question, restore a three-dimensional view of the excavation. Likewise, the stonemason signs have to be mentioned, which could be visualized for the first time and whose distribution pattern within the crypt can be easily understood in this way.

The imported data can be explored further by querying the attribute table connected to it or changing the visualization of specific attributes within a layer in order to recognize patterns. In the case of 
stonemason signs, only the sign associated with one stone mason could be highlighted, so as to visualize the areas of construction in which he was active. An example of the recognition of patterns by changing the visualization of a specific attribute is a different representation of the material of the stones in the foundation wall visible in a section (Fig. 7).

The available datasets can also be used to create new quantitative or interpretational information. The former can be produced, for example, from the vectorized section drawings of the previous examples. More specifically, the stones, which are now represented as polygons, have been automatically stored in the attribute table, along with their size. This data, if extended to larger parts of the church, can then be used to generate and compare the average size of building stones in different areas or time periods of the structure. New interpretational data can be created by structuring elements of interest (architectonic, decorative, etc.) into different layers, associating them again with more information through their attribute tables (e.g., Fig. 10). Furthermore, wall analysis can be performed directly by drawing on the 3D models (Fig. 4), which constitutes a powerful tool for understanding the building process when it is combined with the visualization and query tools already described.

Visualization is playing a key role in the above described uses of a 3D GIS. In fact, archaeological research depends heavily on discovering patterns and identifying and defining relationships and connections, all of which is heavily influenced by how the available information is visualized. For Llobera, it is surprising that there has not been given much more attention to visualization in archaeology and he argues that its importance and capacities have not been fully acknowledged and explored [Llobera 2011]. Frischer [2008] also emphasized the significance of visualization, citing the information specialist Colin Ware [2004: 3], who describes five ways in which visualization can facilitate understanding and interpretation:

- It may facilitate the cognition of large amounts of data

- It can promote the perception of unanticipated emergent properties

- It sometimes highlights problems in data quality

- It makes clear the relationship of large-and small-scale features

- It helps us to formulate hypotheses

Thus, being able to visualize all the available data on a case study in one environment constitutes a great advantage in interpretation. If and how all the above five points can be addressed in practice by 3D GIS, as presented in this study, has still to be investigated when the system is put to a test and used by archaeologists to answer specific research questions. In order for the system to be fully functional, it has to be expanded and data concerning the entire building has to be integrated. Of crucial importance is also the development and formulation of an adequate ontology. In fact, according to Niccolucci et al., who advocate the importance of ontologies for an efficient and meaningful interpretation, "... data cannot be compared, if the data structures have no clear semantics (identity of concepts employed for data structures), and the provenance of knowledge is not transparent" [2015: 3]. 


\section{CONCLUSIONS}

This study has shown how old and new datasets related to building archaeology, acquired with different methods and over a time period of a century, can be integrated into one three-dimensional platform. The implemented data can be visualized, queried and manipulated in novel ways that would not be possible without the use of a 3D GIS. Of crucial importance is the simultaneous development of an ontology and an appropriate data structure for the system in order to exploit its full potential.

The goal of such a platform is to facilitate interpretation and understanding of the information and material concerning a building for researchers. Thanks to the flexibility of the software and its independence of scale, it is possible to create information systems in a wide range of level of detail, from data regarding entire building sections, to single stones or even marks on stones. Consequently, the amount of data as well as the amount of time and work spent in creating the system will vary substantially. Incorporating all the available datasets on a structure might not be necessary or even desirable, depending on the questions asked. It is thus up to the researcher to decide the level of detail for a project and which combination of datasets are interesting to explore and to integrate into the system.

\section{ACKNOWLEDGEMENTS}

I would like to thank the C. M. Lerici Foundation in Stockholm for funding this project as well as DARK Lab at Lund University for giving me access to their equipment and facility and its members for their support and help in the project. Furthermore, I want to express my gratitude to the "Lund Cathedral 2023" project for their collaboration and for giving me access to their scan data acquired by the company SWECO.

Each photograph and illustration is either my intellectual property or I have received permission from the copyright holder to use it.

\section{REFERENCES}

Giorgio Agugiaro and Fabio Remondino. 2014. 3D GIS for Cultural Heritage Sites: The QueryArch3D Prototype. In Stefano Campana and Fabio Remondino, eds. 3D Modeling in Archaeology and Cultural Heritage - Theory and Best Practices. . BAR International Series 2598. Oxford: Archaeopress, 2014.

Peter Allen et al. (2004). "Seeing into the Past: Creating a 3D Modeling Pipeline for Archaeological Visualization." In Proceedings 3D Data Processing, Visualization \& Transmission (3DPVT '04), Thessaloniki, Greece, Sept. 6-9, 751-758.

Erik Cinthio. 1957. Lunds Domkyrka under Romansk Tid. In Acta Archaeologica Lundensia: Series in 801 . Lund.

James Conolly and Mark Lake. 2004. Geographical Information Systems in Archaeology. Cambridge: Cambridge University Press.

Livio De Luca et al. 2011. A Semantic-Based Platform for the Digital Analysis of Architectural 
Heritage. Computers \& Graphics 35, 2 (2011), 227-41. doi:10.1016/j.cag.2010.11.009.

Nicoló Dell'Unto et al. 2016. Experiencing Ancient Buildings from a 3D GIS Perspective: A Case Drawn from the Swedish Pompeii Project. Journal of Archaeological Method and Theory 23, 1 (2016), 73-94. doi:10.1007/s10816-014-9226-7.

Michael Doneus and Wolfgang Neubauer. 2005. 3D Laser Scanners on Archaeological Excavations. In Proceedings of the XXth International Symposium CIPA, Torino, 226-231.

Maurizio Forte et al. . 2015. Interpretation Process at Çatalhöyük Using 3D. In I. Hodder and A. Marciniak, eds. Themes in Contemporary Archaeology: Assembling Çatalhöyük ., Leeds: Maney Publishing.

Bernard Frischer. 2008. Introduction. From Digital Illustration to Digital Heuristics. In Beyond Illustration: 2D and 3D Digital Technologies as Tools for Discovery in Archaeology, edited by Bernard Frischer and Anastasia Dakouri-Hild. BAR International Series 1805. Oxford: Archaeopress, v-xxiv.

P. Hacıgüzeller. 2012. GIS, Critique, Representation and beyond. Journal of Social Archaeology 12, 2 (2012), 245-63. doi:10.1177/1469605312439139.

D. M. Jones. 2011. 3D Laser Scanning for Heritage. Advice and Guidance to Users on Laser Scanning in Archaeology and Architecture. 2nd ed. Swindon: English Heritage Publishing.

Markos Katsianis et al. 2008. A 3D Digital Workflow for Archaeological Intra-Site Research Using GIS. Journal of Archaeological Science 35, 3(2008), 655-67. doi:10.1016/j.jas.2007.06.002.

Micheline Kurdy et al.2011. 3D Virtual Anastylosis and Reconstruction of Several Buildings in the Site of Saint-Simeon, Syria. In The 4th International Workshop 3D-ARCH 2011 "3D Virtual Reconstruction and Visualization of Complex Architectures" 2-4 March 2011, Trento, Italy, 45-52.

Giacomo Landeschi et al. 2016. 3D-GIS as a Platform for Visual Analysis: Investigating a Pompeian House. Journal of Archaeological Science 65, 1 (2016), 103-13. doi:10.1016/j.jas.2015.11.002

Marcos Llobera. 2011. Archaeological Visualization: Towards an Archaeological Information Science (AISc). Journal of Archaeological Method and Theory 18, (2011), 193-223. doi:10.1007/s10816-0109098-4.

Gary Lock. 2001. Theorising the Practice or Practicing the Theory: Archaeology and GIS. Archaeologia Polona 39 (2001), 153-64.

L.-M. Losier et al. 2007. 3D Geometrical Modeling of Excavation Units at the Archaeological Site of Tell 'Acharneh (Syria). Journal of Archaeological Science 34, 2 (2007), 272-88. doi:10.1016/j.jas.2006.05.008.

Franco Niccolucci et al. 2015. "The Formal Logical Foundations of Archaeological Ontologies.pdf." In Mathematics and Archaeology. Boca Ratan [FL]: CRC Press 86-99.

Otto Rydbeck. 1953. Lundensiska Stenhuggarmärken. Lund, 1953.

Thomas Rydén and Björn Lovén. 1995. Domkyrkan I Lund. Malmö : Corona.

Colin Ware. 2004. Information Visualization: Perception and Design. 2nd ed. Amsterdam: Elsevier Science \& Technology Books.

David Wheatley and Mark Gillings. 2002. Spatial Technology and Archaeology: The Archeaological Applications of GIS. New York: Taylor \& Francis.

Received March 2017; revised July 2017; accepted August 2017.

Studies in Digital Heritage, Vol. 1, No. 2, Publication date: December 2017 